\title{
Influence of buildings aerodynamic characteristics on the calculation of infiltration losses results
}

\author{
Dmitry Gribach ${ }^{1}$, Julia Gribach ${ }^{1, *}$, and Pavel Churin ${ }^{1}$ \\ ${ }^{1}$ Moscow State University of Civil Engineering, Yaroslavskoe shosse, 26, Moscow, 129337, Russia
}

\begin{abstract}
This work is devoted to the problem of studying the energy efficiency of buildings, in particular - the definition of infiltration losses. The article presents the main methods for determining infiltration, which are presented in SP 50.133330.2012 and GOST R 55656-2013. However, the infiltration of air through the building envelope depends largely not only on the structural and planning features of the building, installed equipment, etc., but also on the environment, the climatic characteristics of the region in particular the effect of wind. In this regard, the staff of the Educational, scientific and industrial laboratory for aerodynamic and aeroacoustic tests of building structures of the NRU MGSU developed an addition to the existing established algorithms for calculating infiltration using the data of the experimental wind impact study, which is presented in this paper. The publication contains a description of the main stages of the implementation of this type of work.
\end{abstract}

\section{Introduction}

Efficient use of energy is one of the priorities of our time. Competent exploitation of resources and devices that consume energy, new technologies and developments in energy, engineering, energy consumption, and construction are all key aspects of energy efficiency.

Today, there are a large number of normative technical documents related to the regulation of energy efficiency building projects $[1,2,3]$. However, these data require constant adjustment in the development of new technologies, design solutions and due to scientific progress in the use of secondary energy resources [4, 5].

One of the main aspects of the studied subject is the process of air infiltration through the permeable elements of the enclosing structures of buildings. It is the movement of air through the enclosing structures from the environment into the premises due to the wind and thermal head formed by the temperature difference and the pressure drop of air outside and inside the premises $[3,5,6]$. This process is considered the norm, if the amount of incoming air is sufficient for the proper operation of heating systems $[7,8,9]$.

\footnotetext{
* Corresponding author: js-995@mail.ru
} 


\section{Basic methods for calculating infiltration losses}

The main document in the field of studying energy efficiency is SP 50.13330.2012 «Thermal protection of buildings» [1]. In this normative document are given the basic requirements for enclosing structures, which must be observed to ensure: the specified parameters of the microclimate; thermal protection; protection against waterlogging of enclosing structures; efficiency of heat energy consumption for heating and ventilation; necessary reliability and durability of structures. The code also contains information on how to determine the amount of infiltrating air entering the stairwell of a residential building or a premises in a public building through leakage of openings when they are located on the windward side (1):

$$
G_{\text {inf }}=\left(\mathrm{A}_{w} / \mathrm{R}_{u, w}^{r e q}\right)\left(\Delta \mathrm{p}_{w} / 10\right)^{2 / 3}+\left(\mathrm{A}_{d} / \mathrm{R}_{u, d}^{r e q}\right)\left(\Delta \mathrm{p}_{d} / 10\right)^{1 / 2}
$$

where $\mathrm{G}_{\text {inf }}$ - amount of infiltrating air;

$\mathrm{A}$ - the area of windows and doors, $\mathrm{m} 2$;

$\mathrm{R}$ - required resistance to air permeability of windows and doors:

$\Delta \mathrm{p}$ - the difference in air pressures of windows and doors on the outer and inner surfaces of the enclosing structures, $\mathrm{Pa}(2)$ :

$$
\Delta \mathrm{p}=0,55 H\left(\gamma_{\text {out }}-\gamma_{\text {in }}\right)+0,03 \gamma_{\text {out }} v^{2}
$$

where $\mathrm{H}$ - building height, $\mathrm{m}$;

$\gamma_{\text {out }}, \gamma_{\text {in }}$ - specific gravity of the external and internal air, $\mathrm{N} / \mathrm{m}^{3}$, determined by the 3 :

$$
\gamma=\frac{3463}{(273+t)}
$$

where $\mathrm{t}$ - internal and external air temperature.

The drawback of this method lies in the initially large stock of values, which means that in order to carry out construction work, materials with overstated technical requirements are required. From the point of view of exploitation, this is good, but for economic expediency a different approach is needed.

It is important to note that the study of energy efficiency is associated with thermal losses of buildings and structures. Infiltration of air through the building envelope depends largely not only on the structural and planning features of the building, installed equipment, etc., but also on the environment, namely the climatic characteristics of the region, in particular - the effect of wind.

Description of the alternative version of the calculation of infiltration losses that takes into account the wind impact is presented in GOST R 55656-2013 «Energy characteristics of buildings» [2]. In this normative document, the flow of infiltration air through the airpermeable building element can be calculated using 4 (for windows) and 5 (for doors):

$$
\begin{aligned}
& G_{\text {inf }}=\left(1 / \mathrm{R}_{\text {inf }, w}\right)\left(\Delta p / \Delta p_{0}\right)^{2 / 3} \\
& G_{\text {inf }}=\left(1 / \mathrm{R}_{\text {inf }, d}\right)\left(\Delta p / \Delta p_{0}\right)^{1 / 2}
\end{aligned}
$$

The calculated pressure difference $\Delta \mathrm{p}, \mathrm{Pa}$, is found by the (6):

$$
\Delta P=(\mathrm{H}-\mathrm{h})\left(\gamma_{\text {out }}-\gamma_{\text {in }}\right)+\left(\rho_{\text {out }} \mathrm{v}_{\text {out }}^{2} / 2\right) \mathrm{k}_{d y n}\left(\mathrm{c}_{w}-\mathrm{c}_{l}\right)-\mathrm{P}_{\text {in }}
$$


where $\mathrm{k}_{\mathrm{dyn}}$ - the coefficient by which the change in the dynamic properties of the wind in the residential development is taken into account, depending on the type of terrain;

$\mathrm{c}_{\mathrm{w}}, \mathrm{c}_{1}$ - aerodynamic coefficients on the windward and leeward facades. The GOST contains the approved values of these coefficients: $\mathrm{c}_{\mathrm{w}}=0,8, \mathrm{a} \mathrm{c}_{\mathrm{l}}=-0,6$.

However, this method in the presence of a more accurate approach for determining values of infiltration has a similar procedure SP drawback - stock.

With the purpose of getting close to reality the results of the calculation, the staff of the Educational, scientific and industrial laboratory for aerodynamic and aeroacoustic tests of building structures of the NRU MGSU developed an addition to the existing established algorithms for calculating infiltration using data from an experimental study of wind impact [4].

\section{Algorithm of research}

Determination of air infiltration through the air-permeable building element according to GOST R 55656-2013 [2] is possible taking into account the data obtained by conducting experimental studies of the aerodynamic characteristics of the buildings. For this purpose, a was developed technique for performing physical modeling of the wind impact on a building object [10]. The data of the experimental study make it possible to obtain the most accurate and reliable result of the calculation of air infiltration.

The process of conducting experimental studies is divided into stages and should be performed in the following order:

- Analysis of the climatic characteristics of the terrain (including topographic and meteorological data analysis). Based on the results of the climatic analysis of the territory, working zone of wind tunnel is prepared out for carrying out experimental studies.

- Design and manufacture of the test object layout on a smaller scale. First of all, it is important to determine the main building parameters: the location of buildings and structures, the scale of the model, on the basis of which the model of the object is created on the basis of the theory of geometric similarity.

- The next step is the installation of the model in the wind tunnel with the preliminary installation of pressure sensors. The investigated model is placed on the automated rotary table, located in the working area of wind tunnel.

- Conducting experimental studies in a specialized wind tunnel with subsequent processing of the results. Experimental studies are carried out in the Large Gradient Wind Tunnel of the NRU MGSU. With the help of specialized software LabView defined readings of pressure sensors at a flow rate in the tube of about $10 \mathrm{~m} / \mathrm{s}$ for 8 angles of attack $[3,4]$.

- Processing of the results. In the course of performing the experimental studies, the aerodynamic coefficients $\mathrm{Cp}$ are determined. The obtained values of the aerodynamic coefficient are used in the formula for finding the differential pressure $\Delta \mathrm{P}$ on the different sides of the air-permeable building element.

\section{Approbation of the methodology}

The object of the study is a residential complex located in the south-east of Moscow. The projected complex is a group of residential buildings. The maximum height of the building is about $100 \mathrm{~m}$ (Figure 1). Buildings of the complex are constructions of different number of storeys: from $30 \mathrm{~m}$ to $100 \mathrm{~m}$. The maximum number of storeys of the complex is 32 floors, the minimum - 6 floors. Type of residential complex: combined. 


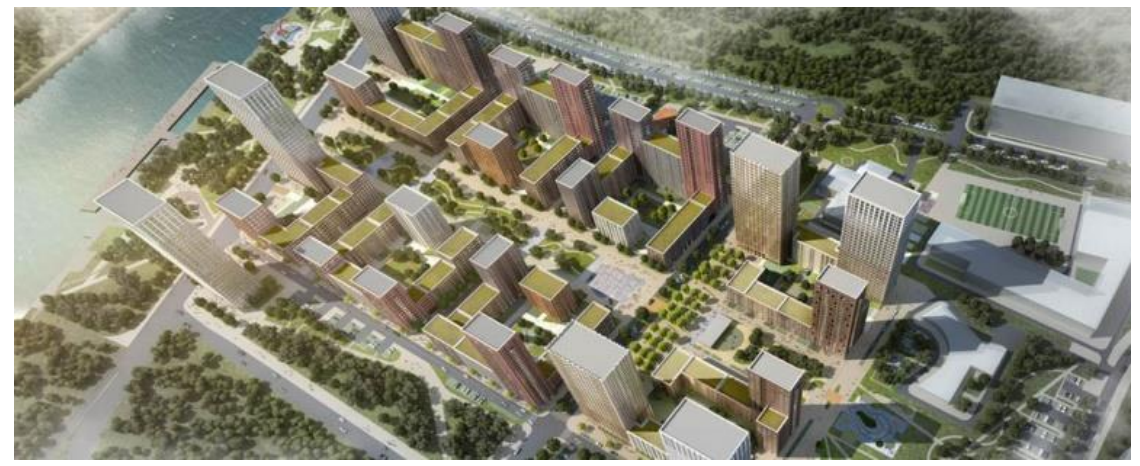

Fig. 1. The object of the study

For experimental research, a model of a residential complex was developed and manufactured. Taking into account the dimensions of the working part of the wind tunnel, the maximum possible scale of 1:250 was chosen from the clutter conditions of the flow.

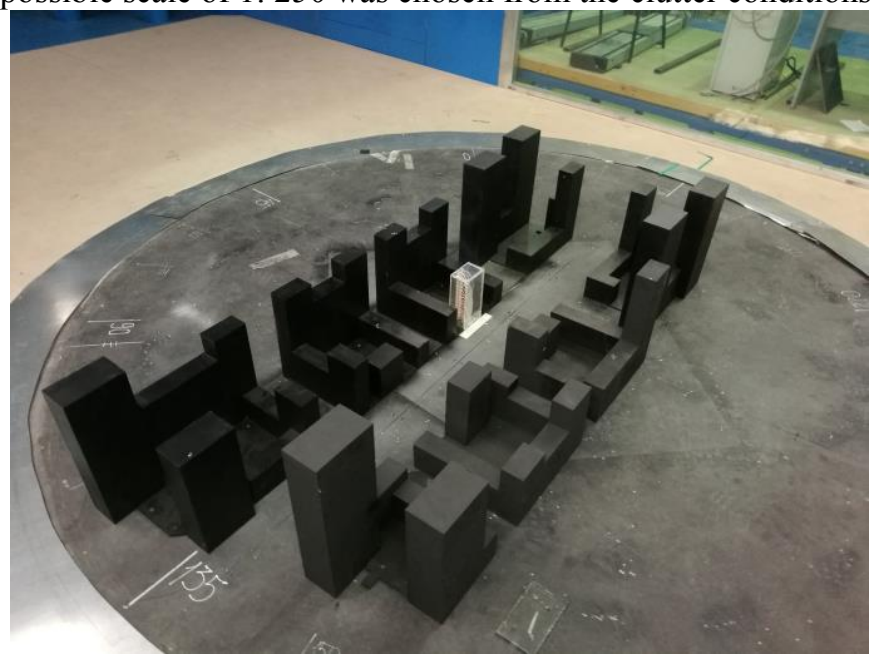

Fig. 2. Model of a residential complex

In the process of preparation for the experimental study, the model was drained: 33 pressure sensors were installed along the facade of the building. The experiment was carried out at 8 angles of attack (from 0 to 315), the flow velocity in the working zone reached $12 \mathrm{~m} / \mathrm{s}$.

\section{Conclusions}

The obtained results showed that it is possible to further refine the results of calculating the infiltrating air (according to GOST R.55656-2013) by using the values of the aerodynamic coefficients obtained during the experimental study. This option allows the most accurate use of aerodynamic characteristics of the building, namely:

- the shape of the building;

- the influence of the surrounding buildings;

- different directions of air flows along the wind rose.

The value of infiltrated air is further reduced by $18-32 \%[4,11,12]$, depending on the conditions of the experimental studies (without regard to the surrounding buildings and with it). 
The work was financial supported by the Ministry of Education and Science of the Russian Federation within the framework of the state \#7.6075.2017/8.9, Project «Investigation of the phenomena of aerodynamic instability of building structures in aero-elastic statement, including the development of an innovative methodology for analysing meteorological data to refine the parameters of the wind load».

All tests were carried out using research equipment of the unique scientific installation «Large Research Gradient Wind Tunnel» of The Head Regional Shared Research Facilities of the Moscow State University of Civil Engineering.

\section{References}

1. SP 50.13330.2012 Thermal performance oh the buildings

2. GOST R 55656-2013 Energy performance of buildings

3. P. Yi, L. Lingjiao, M. Cunming, L. Nan, Industrial Construction, 9, 031 (2014)

4. D. Gribach, A. Kubenin, O. Poddaeva, Book series AISC, 692, 490-497 (2017)

5. B. Aksenov, S. Karyakina, Mathematical and Informational Modeling: Sat. sci. works, 4, 102-110 (2002)

6. Z. Bai, Environment Pollution \& Control, 28 (2006)

7. M. Prignon, G. Moeseke, Energy \& Buildings, 146, 87-97 (2017)

8. X. Wang, C. Kendrick, R. Ogden, N. Walliman, B. Baiche, Applied Energy, 104, 337344, 2013)

9. Y. Chen, J. Liu, J. Pei, X. Cao, Q. Chen, Y. Jiang, Energy and Buildings, 73, 184-191 (2014)

10. L. Ng, A. Musser, A. Persily, S. Emmerich, Energy and Buildings, 58, 11-18 (2013)

11. S. Chen, M. Levine, H. Li, P. Yowargana, L. Xie, Energy and Buildings, 51, 157-164 (2012)

12. N. Heijmans, P. Wouters, Technical Report, 35 (2002) 